\title{
Performance of waterjet on cutting maize stalks: A preliminary investigation
}

\author{
Hongnan Hu, Hongwen Li*, Qingjie Wang, Jin He, Caiyun Lu, Yingbo Wang, Chunlei Wang \\ (College of Engineering, China Agricultural University, Beijing 100083, China)
}

\begin{abstract}
Large amounts of crop stalks left in the field as a result of conservation agriculture cause blockage during no-till planting. To solve this issue, pure waterjet was used to cut off the maize stalks so that the rear furrow opener could pass through without blockage. In this investigation, an experimental study on depth of cut, which was the main performance indicator of pure waterjet on cutting maize stalks, was presented. A full factorial design with 200 tests was implemented with respect to three operation parameters, that is traverse speed, waterjet pressure, and standoff distance were considered as variables. An analysis of variance (ANOVA) was carried out in order to determine the statistical significance of individual operation parameters. Using multilinear stepwise regression analysis, a model to predict the cut of depth from the predicted pure waterjet operation to cut maize stalks was then developed. All three operation parameters significantly influenced the cutting performance. Moreover, the results indicated that depth of cut increased with the increase of waterjet pressure, the decrease of traverse speed, and decrease in standoff distance. Waterjet pressure provided major contribution to depth of cut, followed by traverse speed, then standoff distance, which was demonstrated by both ANOVA and regression analysis. The experimental results showed that when the standoff distance was closer than $10 \mathrm{~mm}$ and waterjet pressure was $280 \mathrm{MPa}$, all maize stalks specimen could be cutoff thoroughly. With the consideration of field operating conditions, waterjet pressure of $280 \mathrm{MPa}$ or higher and $10 \mathrm{~mm}$ to $15 \mathrm{~mm}$ standoff distance were recommended for maize stalks cutting. This analysis provided a realistic approach for the optimization of the ultra-high pressure pure waterjet parameters in maize stalks cutting, which could be used to relieve the occurrence of straw blockage in no-till planting.
\end{abstract}

Keywords: waterjet, ultra-high pressure, conservation tillage, maize stalks, cutting, traverse speed, standoff distance DOI: $10.25165 /$ j.ijabe. 20191205.5088

Citation: Hu H N, Li H W, Wang Q J, He J, Lu C Y, Wang Y B, et al. Performance of waterjet on cutting maize stalks: A preliminary investigation. Int J Agric \& Biol Eng, 2019; 12(5): 64-70.

\section{Introduction}

Conservation agriculture (CA) advocates no or minimum soil disturbance, biomass mulch soil cover, and crop species diversification in agricultural practices ${ }^{[1]}$. $\mathrm{CA}$ is capable of mitigating the concerns of land resource degradation, as well as reducing the contribution to climate change by reducing greenhouse gas emissions and contributing to carbon sequestration in soil. Thus, one of the key operations of CA is no-till direct seeding on biomass mulch cover land, which consequently creates higher demands on seeding machinery ${ }^{[2,3]}$. In the North China Plain, the most popular cropping system is to grow two successive crops $^{[4]}$, maize as summer crop and wheat as winter crop, within

\section{Received date: 2019-04-20 Accepted date: 2019-09-23}

Biographies: Hongnan $\mathrm{Hu}, \mathrm{PhD}$ candidate, research interests: conservation agriculture machinery, Email: hongnanhu@qq.com; Qingjie Wang, PhD, Professor, research interests: conservation tillage and equipment. Email: wangqingjie@cau.edu.cn; Jin He, PhD, Professor, research interests: conservation agriculture and farm machine, Email: hejin@cau.edu.cn; Caiyun Lu, $\mathrm{PhD}$, Associate Professor, research interests: precision agriculture technology and equipment, Email: lucaiyun@cau.edu.cn; Email: lhwen@ cau.edu.cn; Yingbo Wang, $\mathrm{PhD}$ candidate, research interests: conservation agriculture machinery, Email: wangyingbocau@163.com; Chunlei Wang, PhD candidate, research interests: conservation agriculture machinery, Email: chlwang@cau.edu.cn.

*Corresponding author: Hongwen Li, PhD, Professor, research interests: conservation agriculture, agriculture machine and equipment engineering. College of Engineering, China Agricultural University, No.17, Qinghua East Road, Haidian District, Beijing 100083, China. Tel: +86-10-62737300, Email: lhwen@cau.edu.cn. the same year. Winter wheat should be directly drilled into the stubble of summer maize. Furrow opener could affect soil bulk density, cone index, sowing performance, and seed emergence ${ }^{[5,6]}$, thus the performance of furrow opener of a no-till seeder for winter wheat has great influence on crop growth. To ensure sufficient a growth period, wheat must be seeded immediately after maize harvesting. However, a large amount maize stalks/residue is relatively fresh and hard to cut following the maize harvest. This poses a dilemma in the summer maize and winter wheat cropping system, such that large amounts of maize residue could cause plugging of furrow openers and metering devices ${ }^{[7]}$.

To tackle the dilemma, researchers designed several kinds of furrow openers or anti-blocking devices with different working principles. Rolling coulter was used on seeders to clean the seedbed before the furrow opener engages soil ${ }^{[8]}$ Also, double discs furrow opener are designed to improve the ability of soil penetration and residue cutting ${ }^{[9]}$. Coulters are the least intrusive yet effective vertical tools to slice soil and cut residue ${ }^{[10]}$. Despite this, coulters are large in diameter and the vertical cutting force is mainly provided by gravity, which means seeders with such furrow openers usually are large in scale, heavy in weight, and of great demand in draft force. Specifically, in two crops a year areas in China, maize has only been harvested while its straw is tough, and may therefore be pressed into the soil rather than being cut by the discs. Meanwhile, strip-chop and strip-till ${ }^{[4,8]}$, which cut straw by rotary blades, are also put forward. On the other hand, straw may wind around the blade roller, and straw cutting quality does not always meet seeding requirements. Therefore, a new form of furrow opener needs to be developed to cut fresh straw residue 
easily, especially in the two crops a year areas. $\mathrm{Hu}$ et al. ${ }^{[12]}$ proposed an ultra-high pressure (UHP) waterjet pre-opener for no-till seeder and attempted to solve aforementioned problems.

Currently, waterjet (WJ) cutting is one of the fastest growing non-conventional technologies among manufacturing machinery ${ }^{[13]}$. During the cutting process, water is pumped at a sufficiently high pressure (200-400 MPa) and discharged through a small diameter orifice (0.2-0.4 mm dia.). The potential energy of water is converted into kinetic energy, yielding an ultrasonic velocity jet. The WJ cutting technology has various distinct advantages, and is widely used for cutting applications. In agriculture, cutting is used in various operations, such as slashing weeds, chopping straw, reaping crops, and opening soil or slicing stubbles. The cutting of various agricultural materials using high pressure water jet thus presents a promising approach. With the objective of revealing the cutting process of agricultural materials under $\mathrm{WJ}$, investigation of the effects of water jet parameters on cutting performance is extremely important and highly desirable. Somjet et al. ${ }^{[14]}$ used WJ with a specific cutting energy of $8.7 \times 10^{-3} \mathrm{~J} / \mathrm{mm}^{3}$ to cut sugarcane of $30-\mathrm{mm}$ diameters at a traverse speed of $4.4 \mathrm{~km} / \mathrm{h}$; Dennis et al. ${ }^{[15]}$ used WJ with $150 \mathrm{MPa}$ cutting pressure and $0.6 \mathrm{~mm}$ nozzle diameters to cut sugar beet of $75 \mathrm{~mm}$ diameters at a cutting speed of $1.5 \mathrm{~m} / \mathrm{s}$; Wang et al. ${ }^{[16]}$ used WJ to cut meat with bone at a traverse speed of $1200 \mathrm{~mm} / \mathrm{min}$; John et al. ${ }^{[17]}$ used 206.8 MPa WJ with $0.127 \mathrm{~mm}$ diameter diamond orifice nozzle to cut strawberry calyx. It can be deduced that cutting maize stalks using waterjet is achievable, environmentally friendly, and quality guaranteed. Furthermore, it has become a potential option for anti-block utilization in no till seeding.

The cutting performance of WJ can be predicted based on complex and interacting parameters ${ }^{[18]}$, including both the operation parameters of WJ technology and material characteristics to be cut. Previous studies which were related to WJ cutting agricultural materials evidently showed that there were numerous parameters which have been identified and considered, such as orifice diameters, water pressure, standoff distance and traverse speed. There is a lack of analysis data on the performance of WJ on cutting maize stalks and this information is highly desirable and crucial to guide the design of ultra-high pressure WJ pre-opener equipment.

This study aimed to deal with the blockage issues encountered while seeding winter wheat after summer maize harvest in a no-till field of CA, using waterjet to cut through heavy maize stalks, thus guaranteeing the working quality of furrow opener. For this purpose, the depth of cut represented cutting performance, for there was no requirements for surface quality or kerf profile.

In this preliminary study, a full factorial experimental method was utilized to investigate performance of waterjet on cutting maize stalks. The objective was to examine the effects of operation parameters on the cutting performance, and a multilinear regression model for depth of cut was proposed to effectively control and ultimately optimize the maize stalks cutting process. Furthermore, this study will form a guideline for the design of no-till seeder with WJ pre-opener and the settings of operation parameters.

\section{Materials and method}

\subsection{Materials}

\subsubsection{Maize stalks}

Maize stalks specimen was the fresh maize (ZhengDan 958) planted at Zhuozhou $\left(115^{\circ} 59^{\prime} \mathrm{E}, 39^{\circ} 29^{\prime} \mathrm{N}\right)$ in a two crops a year area of the North China Plain. It was harvested in October 4, 2018 and stored indoors for $7 \mathrm{~d}$ until the experiments carried out. Using the drying method, the average moisture content of the maize stalks was $54.7 \%$. Both long axis diameter and short axis diameter of maize stalks specimen were measured by a vernier caliper with \pm 0.01 accuracy and recorded with 3 times repetition of each position. Short axis diameter ranged from 13.22 to $15.33 \mathrm{~mm}$, while long axis diameter ranged from 28.67 to $31.23 \mathrm{~mm}$. 50 maize stalks specimens were cut into $20 \mathrm{~cm}$ in length for test and cutting points of specimens were all within the internodes. Even though specimens were selected carefully, there were still differences in scales of diameters due to natural variations in growth characteristic.

\subsubsection{Ultra-High pressure (UHP) pure waterjet machine}

This study was conducted on a three-axis pure WJ machine produced by Anhui Aoyu CNC Technology Co., Ltd., driven by a mono intensifier pumping system with continuous operating pressure of up to $360 \mathrm{MPa}$. The highest traverse speed of this machine was $5000 \mathrm{~mm} / \mathrm{min}$ and the maximum flow rate was $3.7 \mathrm{~L} / \mathrm{min}$. The energy resource of this $\mathrm{WJ}$ machine came from a $37 \mathrm{~kW}$ electromotor, and tap water was used as cutting medium after triple filter. In this study, pure waterjet aimed to cut off maize stalks to let the rear furrow opener move forward without blockage, and without any quality requirements for the cutting kerf, a large orifice diameter was selected to provide better cutting ability ${ }^{[19]}$. To clarify, orifice diameters are standard parts in different sizes, and a diameter of $0.3 \mathrm{~mm}$ was selected for maize stalks cutting in order to match the intensifier pump and be suitable for material cutting character. The water pressure originated from the intensifier pump was measured with a pressure gauge in real time. The scheme of maize cutting device was shown in Figure 1.

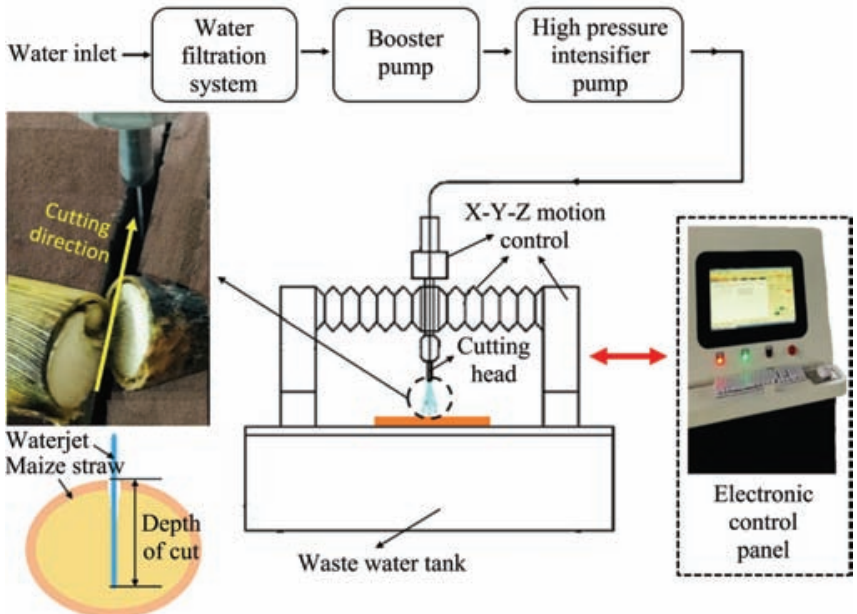

Figure 1 Cutting process of maize stalks under UHP waterjet

\subsection{Experimental procedure}

\subsubsection{Experiment setup}

Although performance of waterjet on cutting maize stalks involves a large number of variables that may somehow affect the results, only major variables were concerned in this study. Based on the previous studies ${ }^{[12-15]}$, three key parameters were selected as water pressure, traverse speed and standoff distance, and a full factorial experimental design was applied. Each parameter was assigned different levels, 10, 5 and 4 levels for water pressure, traverse speed and standoff distance, respectively. The range of parametric conditions is described in Table 1. So that total of 200 combinations were conducted. 
Table 1 Experimental conditions

\begin{tabular}{lc}
\hline Fixed parameters & Values \\
\hline Diameter of orifice & $0.3 \mathrm{~mm}$ \\
Jet impingement angle & $90^{\circ}$ \\
Maxim operation pressure of the machine & $360 \mathrm{MPa}$ \\
Maxim flow rate & $3.7 \mathrm{~L} / \mathrm{min}$ \\
\hline \multicolumn{1}{c}{ Variable parameters } & Levels \\
\hline Water pressure $(P) / \mathrm{MPa}$ & $120,140,160,180,200,220,240,260,280,300$ \\
Traverse speed $(v) / \mathrm{mm} \cdot \mathrm{min}^{-1}$ & $1,000,2,000,3,000,4,000,5,000$ \\
Standoff distance $(S O D) / \mathrm{mm}^{2}$ & $5,10,15,20$ \\
\hline
\end{tabular}

\subsubsection{Depth of cut measurement}

Meanwhile, physical mechanics properties of maize stalks under UHP waterjet were difficult to estimate due to the heterogeneous and anisotropic nature of organic crop straw. It is therefore necessary to set up an evaluation index for the cutting performance. The depth of cut $\left(D_{C}\right)$ represents the capability of waterjet to penetrate into the maize stalks, and was defined as the length from the highest point of maize stalks surface to the deepest point cut by waterjet. The single maize stalks specimen was placed on a soil bin and both ends of the specimen were pinned down; the start position of cutting process was at one side of maize stalks. The cross section of maize stalk was considered as oval shape and waterjet cut through the maize stalks along the direction of long diameter and waterjet injected parallel to the short diameter (as shown in Figure 1). The long diameter $\left(D_{L}\right)$ and short diameter $\left(D_{S}\right)$ of cutting position were measured by electrical vernier caliper at least three times for every cutting operation, and each combination (with the same operation parameters) was repeated three times and the average was taken as the final value for the depth of cut.

In this study, cutting depth was selected to reflect the relationships between operation parameters and cutting performance. Revealer 5F01 high-speed camera was used to record the whole cutting process and cutting depth could be obtained in the photos. For the full frame resolution $(1280 \times 1024)$,

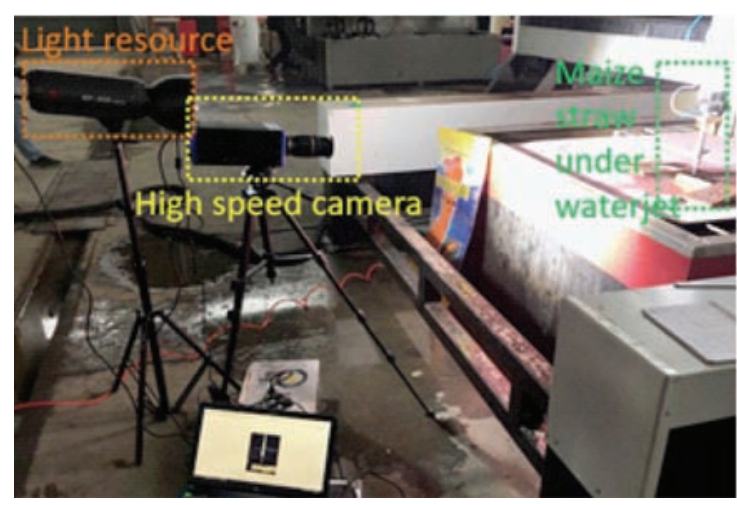

Figure 2 Placement of the experiment

\subsection{Statistical analysis and regression modeling}

ANOVA was utilized (at 95\% confidence interval) to find out the factor's significance for depth of cut as described in Table 1. Design-Expert V8.0.6 was used to calculate the results for the analysis.

A regression model was developed after comprehensively discussing the impact of operation parameters on depth of cut. The equation could help to find out the causal relationships between variables. The value of dependent variables could high frame rate of $2000 \mathrm{fps}$ can be obtained, while in $1024 \times 64$ format, the maximum frame rate is 32000 fps. High-speed camera system was placed at orthographic projection direction (as shown in Figure 2). The exposure time was set as $1 \mathrm{~ms}$, meaning pictures were shot every $1 \mathrm{~ms}$. In particular, threshold time $T_{t}$ was defined as the time that waterjet was away from the maize stalks and not applied on the maize stalks. The threshold time equation was expressed by Equation (1):

$$
T_{t}=\frac{D_{L}}{v}
$$

The pictures were taken right at the threshold time could reflect the depth of cut, and were selected to calculate $D_{C}$. The feature points' image coordinates of these selected high-speed photographs were extracted with MATLAB 14.0. As shown in Figure 3, featured points T, B and, J represented the top point of the maize stalks, the bottom point of the maize stalks and the deepest point of waterjet, respectively. The differences of vertical coordinates could represent the length between two points. With that, the depth of cut could be calculated by Equation (2):

$$
\frac{L_{T B}}{L_{T J}}=\frac{D_{S}}{D_{C}}
$$

where, $L_{T B}$ and $L_{T J}$ are the length of the short axis diameter and depth of cut in high-speed photographs.

The depth of cut represents the capability of the waterjet to penetrate into the maize stalks, and the depth of cut was defined as the longest line from the edge of the maize stalks to the bottle of kerf (as shown in Figures 1 and 3). Natural maize stalks has differences in shape and size; nevertheless, they were carefully selected to be as similar as possible for this experimental test. To access the fairer results, cutoff ratio $\left(R_{c}\right)$ was defined to measure the performance of waterjet cutting as well, $R_{c}$ could be calculated by Equation (3):

$$
R_{C}=D_{C} / D_{L}
$$

where, $R_{c}$ is the cutoff ratio; $D_{c}$ is the depth of cut calculated by high-speed photographs; and $D_{L}$ is the long diameter of the maize stalks specimen measured by vernier caliper.

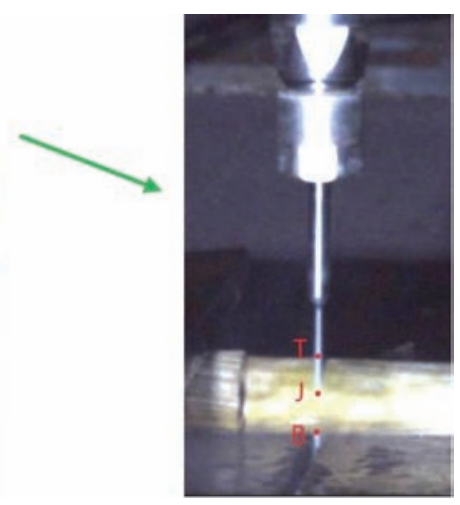

Note: T: top point of the maize stalks; B: bottom point of the maize stalks; $\mathrm{J}$ : the deepest point of waterjet.

Figure 3 High speed photograph of maize stalks

predict the value of independent variables by using suitable regression models ${ }^{[20]}$. The cutting process is complicated and also some unknown parameters which will influence the cutting performance ${ }^{[21]}$. The knowledge and data are limited based on current researches. To simplify the model, depth of cut and operation parameters $(P, v$ and $S O D)$ were taken as the dependent and independent variables, respectively. These parameters can be measured easily and a multilinear stepwise regression model was proposed for the quantification of the depth of cut. Therefore, the 
regression model can be convenient and quick for practical use, and the regression model could be expressed as follows ${ }^{[22]}$ :

$$
Y=b_{0}+b_{1} X_{1}+b_{2} X_{2}+\ldots b_{n} X_{n}
$$

where, $Y$ is the dependent variable; $X_{1} \ldots X_{n}$ are independent variables; $b_{0}$ is the constant and $b_{1} \ldots b_{n}$ accounts for the estimated change in average value of performance feature per unit change in the forecaster value. The statistical analysis was carried out using Statistical Package for Social Sciences (SPSS).

\section{Results and discussion}

High-speed photographs with different operation parameters
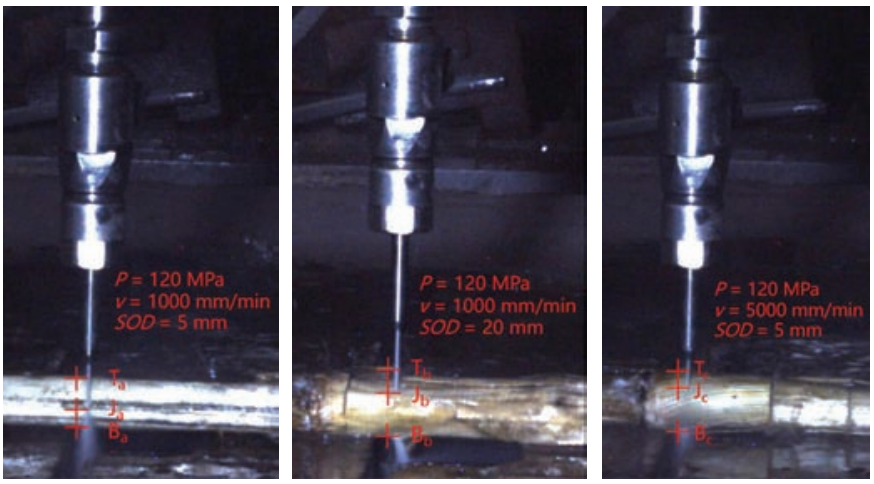

c

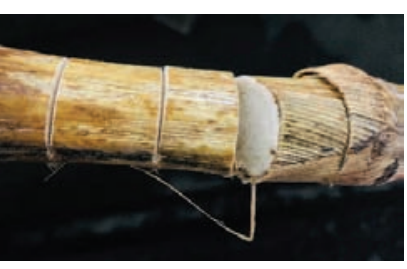

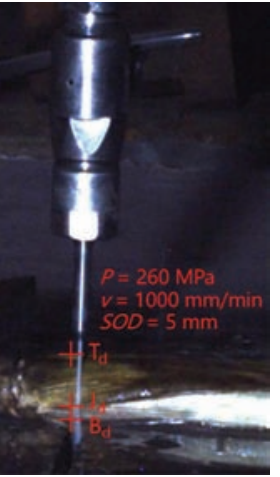

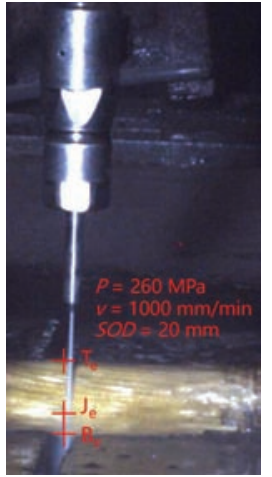

e

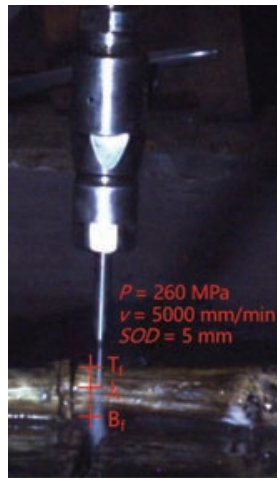

Note: T represents the top point of the maize stalks; B represents the bottom point of the maize stalks; J represents the deepest point of waterjet.

Figure 4 High speed photographs of maize stalks with different operation parameters(a-f), and (g) maize stalks after waterjet cutting

\subsection{ANOVA analysis of the experimental results}

All the selected operation parameters were observed to be significant for the cutoff ratio $\left(R_{c}\right)$ and interactions $\left(P^{*} v, P^{*} S O D\right.$, and $v^{*} S O D$ ) were statistically significant. Furthermore, larger $F$ value indicates that the variables of operation parameters greatly contribute to $R_{c}^{[23]}$. In this study, waterjet pressure $(P)$ leadingly contributed with the $F$ value of 640.08 with regard to the cutoff ratio followed by traverse speed $(v)$ and standoff $(S O D)$ distance with $\mathrm{F}$ value of 381.69 and 147.39 , respectively, as shown in Table 2 .

Table 2 Results of analysis of variance (ANOVA) for the cutoff ratio

\begin{tabular}{cccccc}
\hline Source & $\begin{array}{c}\text { Sum of } \\
\text { Squares }\end{array}$ & df & Mean Square & $F$ Value & $\begin{array}{c}\text { p-value } \\
\text { Prob }>F\end{array}$ \\
\hline Model & 10.77 & 91 & 0.12 & 87.93 & $<0.0001$ \\
$P$ & 7.75 & 9 & 0.86 & 640.08 & $<0.0001$ \\
$v$ & 2.06 & 4 & 0.51 & 381.69 & $<0.0001$ \\
$S O D$ & 0.60 & 3 & 0.20 & 147.39 & $<0.0001$ \\
$P^{*} v$ & 0.26 & 36 & 0.007264 & 5.40 & $<0.0001$ \\
$P^{*} S O D$ & 0.073 & 27 & 0.002719 & 2.02 & 0.0060 \\
$v^{*} S O D$ & 0.031 & 12 & 0.002584 & 1.92 & 0.0396 \\
Residual & 0.15 & 108 & 0.0010346 & & \\
Cor total & 10.92 & 199 & & & \\
\hline
\end{tabular}

Note: The Model F-value of 87.93 implies the model is significant. There is only a $0.01 \%$ chance that a "Model F-Value" this large could occur due to noise. Values of "Prob $>$ F" less than 0.0500 indicate model terms are significant.
Ishfaq et al. ${ }^{[15]}$ found that abrasive waterjet cutting performance was also affected by $P, v$ and $S O D$, with the percentage contributions of $14.2,22.5$ and $9.3 \%$, respectively. Study on surface roughness in waterjet machining ${ }^{[24]}$ also found that $P$ was the most dominant parameter, the following were $v$ and $S O D$, respectively. It could be stated that the contributions of $P$ and $v$ were different between pure waterjet and abrasive waterjet, however, it could be explained that higher $v$ decreased the striking time of abrasive particles and higher $P$ might aggravate the springback of abrasive particles ${ }^{[21]}$, which would obstruct cutting performance of abrasive waterjet. Arola et al. ${ }^{[25]}$ studied the differences of peening performance between pure waterjet and abrasive waterjet and the results were opposite. However, cutting performance of pure waterjet mainly depends on kinetic energy of water flow ${ }^{[16]}$, which makes the waterjet pressure the most important operation parameter for the cutting performance in this study.

\subsection{Influence of operation parameters}

The results of experimental data indicated that $R_{c}$ and $D_{c}$ increased as waterjet pressure increased, and $R_{c}$ had an approximately linear relationship with $P$. Figure 5 demonstrated that as waterjet pressure increased from 120 to $300 \mathrm{MPa}, R_{c}$ and $D_{c}$ increased from 0.202 to 1 , and 3.8 to $21.5 \mathrm{~mm}$, respectively, under different traverse speeds and standoff distances. When the standoff distance was closer than $10 \mathrm{~mm}$, maize stalks specimen could be cut if the waterjet pressure was higher than $280 \mathrm{MPa}$. When the standoff distance was further than $10 \mathrm{~mm}, 300 \mathrm{MPa}$ or 
higher was required to cut through maize stalks. This phenomenon might be related to the larger amount of water flow striking on the cutting surface of maize stalks, which brought higher water energy. This being said, velocity and volume of water striking the maize stalks directly determined cutting performance. To be precise, a certain $0.3 \mathrm{~mm}$ orifice diameter was selected for these experiments, therefore a certain relationship among velocity, water volume, and waterjet pressure was confirmed $^{[26]}$. Assuming water is incompressible, the relationship between the waterjet pressure and the velocity was expressed Bernoulli's Equation (5):

$$
v_{p w j}=\mu_{v} \cdot \sqrt{\frac{2 P}{\rho}}
$$

where, $v_{p w j}$ is waterjet velocity, $\mathrm{m} / \mathrm{s} ; \mu_{v}$ is velocity coefficient, which depends on waterjet and is usually between 0.86 and 0.97 ; $P$ is waterjet pressure, $\mathrm{N} / \mathrm{m}^{2}$; and $\rho$ is water density, $\mathrm{kg} / \mathrm{m}^{3}$. As the $\mu_{v}$ and $\rho$ were constant in this study, the water velocity only depended on waterjet pressure. The kinetic energy of waterjet is directly related to waterjet velocity, so that higher waterjet brought higher kinetic energy.

It was noticed that immediately before the maize stalks were thoroughly cut off, in other words, cutoff ratio attained to $1, D_{c}$ increased rapidly with the increase of $P$. For instance, when the standoff distance was $10 \mathrm{~mm}$, the maize stalks specimen could be fully cut off with a $280 \mathrm{MPa}$ or higher. Meanwhile the difference of $D_{c}$ under $260 \mathrm{MPa}$ and $280 \mathrm{MPa}$ became larger than the lower $P$ (Figure 5b). This might be attributable to the characteristic of waterjet, which could cause the loss of energy when the specimen with crop fiber could not be cut through promptly ${ }^{[27]}$. That is to say, when pure waterjet was subject to resistance from the maize fiber growing along the axial direction, it might wedge into the crack of vascular tissue and finally deteriorated cutting efficiency. Due to this reason, $280 \mathrm{MPa}$ or higher waterjet pressure was recommended as the optional operation parameter for maize stalks cutting.

The influence of the traverse speed on cutting performance was plotted in Figure 5, and demonstrated that increasing traverse speed from 1000 to $5000 \mathrm{~mm} / \mathrm{min}$ effectively reduced $R_{c}$ and $D_{c}$. Under the same $P$ and $S O D$, each decrease of $1000 \mathrm{~mm} / \mathrm{min}$ in traverse speed resulted in a value nearly equal to that of the decline range of $R_{c}$ and $D_{c}$. On that note, the decline range was from 0.6 to $3.4 \mathrm{~mm}$ under operation parameters of $140 \mathrm{MPa}$ waterjet pressure, $15 \mathrm{~mm}$ standoff distance and $240 \mathrm{MPa}, 5 \mathrm{~mm}$ standoff distance, respectively.

Traverse speed somehow relates to striking time of maize stalks under waterjet. When the traverse speed increased, there was fewer water flow striking the maize stalks specimen at a given point. On the other hand, as shown in Figure 5, the rising trend of $R_{c}$ and $D_{c}$ started to level off with the decrease of $v$. For example, under $5 \mathrm{~mm}$ standoff distance, $D_{c}$ increased from 11.6 to $20.1 \mathrm{~mm}$ at a traverse speed of $1000 \mathrm{~mm} / \mathrm{min}$, while $D_{c}$ increased from 5.3 to $20.1 \mathrm{~mm}$ at a traverse speed of $5000 \mathrm{~mm} / \mathrm{min}$. This phenomenon might be attributed to the reduced energy loss. Specifically speaking, the air damping and friction effect on the waterjet decreases as the striking time decreases ${ }^{[28]}$, such that higher $v$ results in less energy loss. In other words, when the waterjet travels fast through the maize stalks, the waterjet cutting efficiency is higher than when it travels slowly. As a result, the rate of decrease in $R_{c}$ and $D_{c}$ will reduce, and the curves consequently level off as $v$ increase.

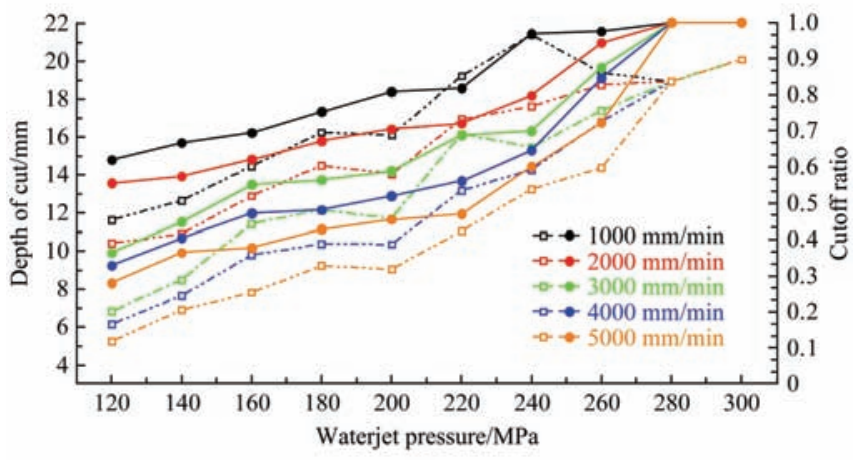

a. Standoff distance $-5 \mathrm{~mm}$

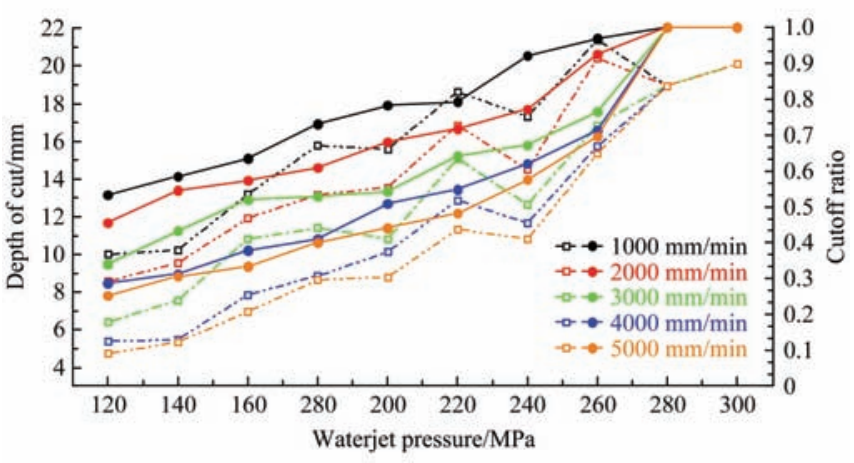

b. Standoff distance $-10 \mathrm{~mm}$

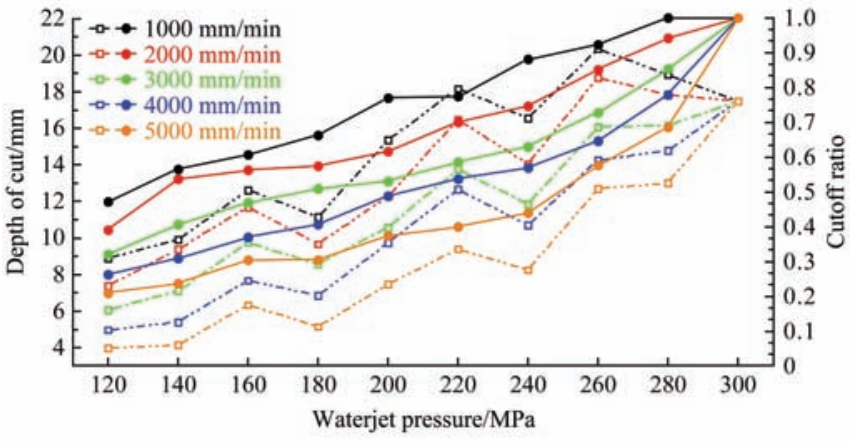

c. Standoff distance $-15 \mathrm{~mm}$

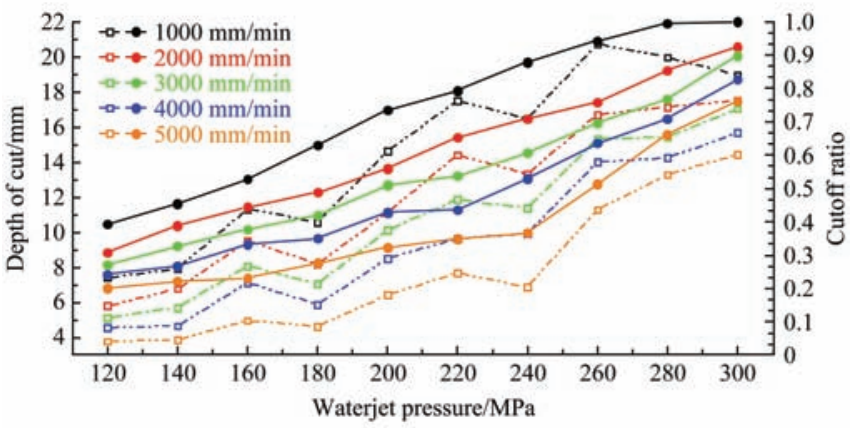

d. Standoff distance $-20 \mathrm{~mm}$

Note: the solid lines represent cutoff ratio and the dotted lines represent depth of cut.

Figure 5 Experimental cutting parameters of maize stalks under pure waterjet

The standoff distance played an inhibiting role in influencing $D_{c}$, as shown in Figure 5. When $P$ was $120 \mathrm{MPa}$ and $v$ was $1000 \mathrm{~mm} / \mathrm{min}, R_{c}$ and $D_{c}$ decreased from 0.62 to 0.39 and from 11.64 to $7.63 \mathrm{~mm}$, respectively, with an increase of $S O D$ from 5 to $20 \mathrm{~mm}$. This might be attributed to the wide waterjet diameter produced by high $S O D$. At higher $S O D$, the energy density of pure waterjet striking decreases, generating a lower waterjet penetration capability as a result ${ }^{[28]}$. Furthermore, the outlet waterjet can be categorized into three zones ${ }^{[14]}$, namely, the solid 
jet zone, the spray zone, and the droplet zone. The solid jet zone has the highest average kinetic energy among all zones. In this zone, the waterjet has strong concentration ability and jet diameter stays still, therefore, in order to acquire higher cutting efficiency, the standoff distance should be limited in the solid jet zone. With an increased distance away from the orifice, kinetic energy decreases along the axis and jet diameter increases due to droplet diffusion. The spray zone and droplet zone contain small droplets mixed with air, which have lower energy and a dramatic decrease in impact capacity; for this reason, the spray zone and droplet zone are not suitable for cutting utilization. Meanwhile, higher SOD led to higher energy consumption caused by the resistance from the water and air mixture ${ }^{[29]}$. Hood ${ }^{[30]}$ suggested positioning the cutting head at a distance within $1 \mathrm{~mm}$ or $2 \mathrm{~mm}$; however, in field application, soil surface is covered with maize stalks, making it hard to keep such little standoff distance. Therefore, to guarantee cutting performance and efficiency, lower $S O D$ is recommended. Meanwhile, in the case of impact damage, the cutting head nozzle tube should avoid impact with stone, soil block, and stubble in the field. There is thus a more stringent requirement for the profiling and protection mechanism of the cutting head when the waterjet is used in the maize stalks mulching field. With this considered, 10-15 mm standoff distance was recommended for maize stalks cutting utilization.

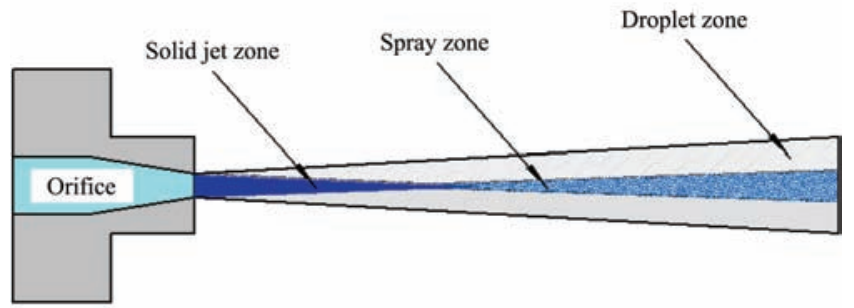

Figure 6 Schematic diagram of waterjet in the air

\subsection{Multilinear stepwise regression analysis}

The statistical results of regression are shown in Table 3, and the following equation was developed:

Depth of cut $(\mathrm{mm})=5.97+0.068 P-0.002 v-0.218$ SOD

where, $P$ is the waterjet pressure, MPa; $v$ is the traverse speed, $\mathrm{mm} / \mathrm{min}$; and $S O D$ is the standoff distance, $\mathrm{mm}$.

The determination coefficient of this model is 0.935 , demonstrating that $93.5 \%$ of the variation in the measured data could be explained by the model in Equation (6).

Table 3 Statistical results from the regression model

\begin{tabular}{|c|c|c|c|c|c|c|c|c|}
\hline \multirow{2}{*}{$\begin{array}{c}\text { Independent } \\
\text { variables }\end{array}$} & \multicolumn{2}{|c|}{ Unstandardized Coefficients } & \multirow{2}{*}{$\begin{array}{c}\text { Standardized Coefficients } \\
\text { Beta }\end{array}$} & \multirow{2}{*}{$t$-value } & \multirow{2}{*}{ Sig. } & \multirow{2}{*}{$\begin{array}{c}\text { Collinearity Statistics } \\
\text { Tolerance }\end{array}$} & \multirow{2}{*}{$F$-ratio } & \multirow{2}{*}{$R^{2}$} \\
\hline & $\mathrm{B}$ & Std.Error & & & & & & \\
\hline (Constant) & 5.973 & 0.411 & & 14.525 & 0.000 & & 805.068 & 0.935 \\
\hline$P$ & 0.068 & 0.002 & 0.803 & 40.373 & 0.000 & 0.979 & & \\
\hline$v$ & -0.002 & 0.000 & -0.545 & -27.677 & 0.000 & 0.999 & & \\
\hline$S O D$ & -0.218 & 0.015 & -0.283 & -14.239 & 0.000 & 0.980 & & \\
\hline
\end{tabular}

The determination coefficient $\left(R^{2}\right)$ of this model is 0.935 , indicating that $93.5 \%$ of the variation in the measured data could be explained by the model in Equation (6); Figure 7 showed that the measured values of $D_{c}$ correlated well with the predicted values. Standardized coefficients could represent the contribution of the independent variables to the dependent variable of this regression model. The best model (i.e. with the highest $R^{2}$ value) derived from the regression analysis suggests that the most significant parameters were (in order from most to least affecting) waterjet pressure, traverse speed, and standoff distance. This result was consistent with the ANOVA analysis as well, in other words, the regression equation was in good agreement with the experimental corresponding data. Although the interaction of three parameters did not take into consideration, the linear regression model could meet the requirements of prediction in a simple approach. In general, these results show that the regression model was statistically significant and that this model may predict depth of cut.

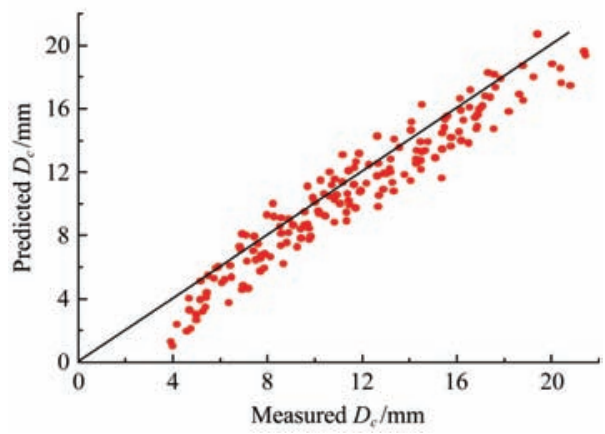

Figure 7 Predicted depth of cut from operation parameters versus measured depth of cut

\subsection{Field test}

A field moving test stand was developed, and a field test was conducted at Zhuozhou Teaching Experimental Station of China Agricultural University in the autumn of 2019 (as shown in Figure 8). The field tests demonstrate the validity of UHP waterjet cutting maize stalks, and the results of field test are consistent with this preliminary investigation. The field test details will be discussed in the further study.

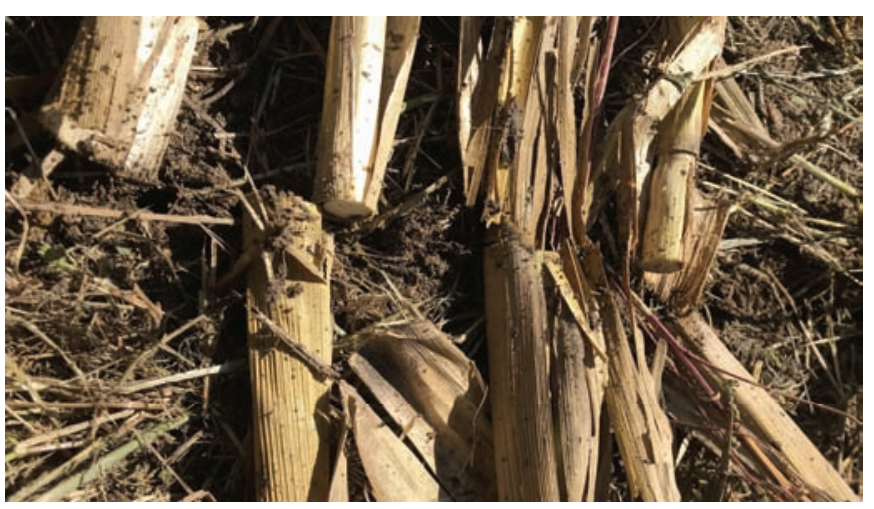

Figure 8 Field test of UHP waterjet cutting maize stalks

\section{Conclusions}

This study mainly investigated waterjet cutting performance of fresh (after harvest) maize stalks. The influences of operation parameters, including waterjet pressure, traverse speed, and standoff distance, on depth of cut were studied. On the basis of experimental results, the main conclusions of the study can be summarized as below: 
From the experimental data, waterjet pressure of $280 \mathrm{MPa}$ and higher was recommended as suitable operation setting, while higher traverse speed resulted in lower depth of cut. Therefore, to ensure time-effectiveness, intermediate traverse speed combined high waterjet pressure was fitted for field practices. Meanwhile, standoff distance should be within $10-15 \mathrm{~mm}$ to ensure the maize stalks were in the region of solid jet zone.

ANOVA analysis showed that all three operation parameters had significant effect on depth of cut as well as cutoff ratio. It was observed that increasing the waterjet pressure resulted in increased depth of cut, while the increase of both traverse speed and cutoff distance led to decreases in the depth of cut. Additionally, based on the results of ANOVA analysis, waterjet pressure made the largest contribution, compared with the other two operation parameters.

A prediction model was derived from a multilinear stepwise regression analysis. The depth of cut was affected by waterjet pressure, traverse speed, and standoff distance. Furthermore, the standardized coefficients showed that waterjet pressure had a great influence on depth of cut, which was consistent with the ANOVA analysis.

With the limitation of experiment equipment and site, the speed of this study was slower than the actual field practice and there will be a further study about the performance of waterjet on cutting maize stalks in fields.

\section{Acknowledgements}

This study was financially supported by the Special Fund for Agro-scientific Research in the Public Interest from the Ministry of Agriculture, China (Grant No. 201503136).

\section{[References]}

[1] Li H, He J, Bharucha ZP, Lal R, Pretty J. Improving China's food and environmental security with conservation agriculture. Int J Agric Sustain, 2016; 14(4): 377-391

[2] Yang L, Zhang R, Gao N, Cui T, Liu Q, Zhang D. Performance of no-till corn precision planter equipped with row cleaners. Int $\mathrm{J}$ Agric \& Biol Eng, 2015; 8(5): 15-25.

[3] He J, Zhang Z, Li H, Wang Q. Development of small/medium size no-till and minimum-till seeders in Asia: A review. Int J Agric \& Biol Eng, 2014; 7(4): 1-12.

[4] $\mathrm{Hu} \mathrm{H}, \mathrm{Lu} \mathrm{C}$, Wang Q, Li H, He J, Xu D, Wang X. Influences of wide-narrow seeding on soil properties and winter wheat yields under conservation tillage in North China Plain. Int J Agric \& Biol Eng, 2018; 11(4): 54-60.

[5] Altikat S, Celik A, Gozubuyuk Z. Effects of various no-till seeders and stubble conditions on sowing performance and seed emergence of common vetch. Soil Tillage Res., 2012; 126: 72-77.

[6] Yao Z, Li H, Gao H, Wang X, He J. Crop performance as affected by three opening configurations for no-till seeder in annual double cropping regions of Northern China. Aust. J. Soil Res., 2009; 47(8): 839-847.

[7] Wang Q, Zhu L, Li M, Huang D, Jia H. Conservation agriculture using coulters: effects of crop residue on working performance. Sustain., 2018; 10(11): 1-15.

[8] Fallahi S, Raoufat M H. Row-crop planter attachments in a conservation tillage system: A comparative study. Soil Tillage Res., 2008; 98(1): $27-34$
[9] Wang C, Liu C, Li H, Wang Q, He J, Caiyun L. Design and experiment of asymmetric large-small double discs ditching device. Transactions of the CSAE, 2018; 34(18): 28-36. (in Chinese)

[10] Zeng Z, Chen Y. The performance of a fluted coulter for vertical tillage as affected by working speed. Soil Tillage Res, 2018; 175(April 2017): $112-118$.

[11] Zhang Z, Jia H, Sun J. Review of Application of Biomimetics for Designing Soil-Engaging Tillage Implements in Northeast China. Int. J. Agric. Biol. Eng. 2016; 9(4): 12-21.

[12] Hu H, Chen W, Li H, Wang Q, He J, Lu C, et al. Design and simulation research of ultra high pressure water-jets pre-opener for no-till planter. 2017 ASABE Annu. Int. Meet. Spons. by ASABE Spokane, Washingt, 2017; Paper No. 1700944

[13] Wang J, Kuriyagawa T, Huang C. An experimental study to enhance the cutting performance in abrasive waterjet machining. Mach. Sci. Technol, 2003; 7(2): 191-207.

[14] Thanomputra S, Kiatiwat T. Simulation study of cutting sugarcane using fine sand abrasive waterjet. Agric. Nat. Resour., 2016; 50(2): 146-153.

[15] Juenemann D, Harms H-H. Development of a water catcher for high pressure. In CIGR XVIIth World Congr. Québec City, 2010; 1-9.

[16] Wang J, Shanmugam D K. Cutting meat with bone using an ultrahigh pressure abrasive waterjet. Meat Sci., 2009; 81(4): 671-677.

[17] Lin J, Holmes M, Vinson R, Ge C, Pogoda F C, Mahon L, Gentry R, Seibel $\mathrm{G}$ E, Chen $\mathrm{X}$, Tao $\mathrm{Y}$. Design and testing of an automated high-throughput computer vision guided waterjet knife strawberry calyx removal machine. J. Food Eng., 2017; 211: 30-38.

[18] Nguyen T, Wang J, Li W. Process models for controlled-depth abrasive waterjet milling of amorphous glasses. Int. J. Adv. Manuf. Technol, 2015; 77(5-8): 1177-1189.

[19] Sun Xudong. Research on key technologies of a high pressure waterjet cutting system. Huazhong University of Science and Technology, 2013.

[20] Aydin G, Karakurt I, Aydiner K. Prediction of the cut depth of granitic rocks machined by abrasive waterjet (AWJ). Rock Mech. Rock Eng, 2013; 46(5): 1223-1235.

[21] Xu S, Wang J. A Study of abrasive waterjet cutting of alumina ceramics with controlled nozzle oscillation. Int. J. Adv. Manuf. Technol, 2006; 27(7-8): 693-702.

[22] Axinte D A, Srinivasu D S, Kong M C, Butler-Smith P W. Abrasive waterjet cutting of polycrystalline diamond: A preliminary investigation. Int. J. Mach. Tools Manuf, 2009; 49(10): 797-803.

[23] Tosun N, Cogun C. An investigation on wire wear in wedm. J. Mater Process. Technol., 2003; 134(3): 273-278.

[24] Caydas U, Hascalik A. A Study on surface roughness in abrasive waterjet machining process using artificial neural networks and regression analysis method. J. Mater. Process. Technol., 2008; 202(1-3): 574-582.

[25] Arola D, McCain M L, Kunaporn S, Ramulu M. Waterjet and abrasive waterjet surface treatment of titanium: A comparison of surface texture and residual stress. Wear, 2001; 249(10-11): 943-950.

[26] Den Dunnen S, Kraaij G, Biskup C, Kerkhoffs GMMJ, Tuijthof GJM. Pure waterjet drilling of articular bone: An in vitro feasibility study. Stroj. Vestnik/Journal Mech. Eng., 2013; 59(7-8): 425-432.

[27] Li M, Huang M, Yang X, Li S, Wei K. Experimental study on hole quality and its impact on tensile behavior following pure and abrasive waterjet cutting of plain woven CFRP laminates. Int. J. Adv. Manuf. Technol., 2018; 99(9-12): 2481-2490.

[28] Karakurt I, Aydin G, Aydiner K. An Experimental study on the depth of cut of granite in abrasive waterjet cutting. Mater. Manuf. Process, 2012; 27(5): 538-544.

[29] Xue Y, Si H, Xu D, Yang Z. Experiments on the microscopic damage of coal induced by pure water jets and abrasive water jets. Powder Technol., 2018; 332(2017): 139-149.

[30] Hood M. Waterjet-assisted rock cutting systems? the present state of the art. Int. J. Min. Eng., 1985; 3(2): 91-111. 